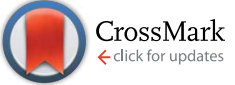

Cite this: RSC Adv., 2016, 6, 2259

Received 23rd September 2015 Accepted 20th December 2015 DOI: $10.1039 / \mathrm{c} 5 \mathrm{ra19616g}$

www.rsc.org/advances

\section{Facile synthesis of mesoporous carbon nanocomposites from natural biomass for efficient dye adsorption and selective heavy metal removal $\dagger$}

\author{
Long Chen, ${ }^{a}$ Tuo Ji, ${ }^{a}$ Liwen Mu, ${ }^{a}$ Yijun Shi, ${ }^{b}$ Logan Brisbin, ${ }^{a}$ Zhanhu Guo, ${ }^{c}$ \\ Mohammel A. Khan, ${ }^{d}$ David P. Young ${ }^{d}$ and Jiahua Zhu*a
}

\begin{abstract}
Mesoporous carbon with embedded iron carbide nanoparticles was successfully synthesized via a facile impregnation-carbonization method. A green biomass resource, cotton fabric, was used as a carbon precursor and an iron precursor was implanted to create mesopores through a catalytic graphitization reaction. The pore structure of the nanocomposites can be tuned by adjusting the iron precursor loadings and the embedded iron carbide nanoparticles serve as an active component for magnetic separation after adsorption. The microstructure of the nanocomposites was carefully investigated by various characterization techniques including electron microscopy, X-ray diffraction, surface analyzer, magnetic property analyzer and etc. The newly created mesopores are demonstrated as a critical component to enhance the adsorption capacity of organic dyes and embedded iron carbide nanoparticles are responsible for the selective removal of heavy metal ions $\left(\mathrm{Zn}^{2+}, \mathrm{Cu}^{2+}, \mathrm{Ni}^{2+}, \mathrm{Cr}^{6+}\right.$ and $\left.\mathrm{Pb}^{2+}\right)$. Isotherm adsorption, kinetic study at three different temperatures $\left(25,45\right.$ and $65^{\circ} \mathrm{C}$ ) and cycling retention tests were performed to understand the adsorptive behavior of the nanocomposites with organic dyes (methylene blue and methyl orange). Together with the preferable removal of more toxic heavy metal species $\left(\mathrm{Cr}^{6+}\right.$ and $\left.\mathrm{Pb}^{2+}\right)$, these mesoporous nanocomposites show promising applications in pollutant removal from water. The facile material preparation allows convenient scale-up manufacturing with low cost and minimum environmental impact.
\end{abstract}

\section{Introduction}

Sustainable clean water supply has been an increasingly serious issue nowadays since significant amounts of surface and ground water have been severely polluted by industrialization of human society. Water pollution has been recognized as the leading worldwide cause of death and diseases, which accounts for the deaths of more than 14000 people daily. ${ }^{1-3}$ The hazards can be roughly classified into three categories: organic, inorganic and biological pollutants. Targeting different pollutants, miscellaneous water remediation technologies have been developed including adsorption, ${ }^{4-9}$ coagulation, ${ }^{\mathbf{1 0}}$ membrane separation, ${ }^{11-13}$ ion exchange, ${ }^{\mathbf{1 4 , 1 5}}$ electrochemical precipitation $^{\mathbf{1 6 , 1 7}}$ etc. Among these technologies, adsorption seems the

Intelligent Composites Laboratory, Department of Chemical and Biomolecular Engineering, The University of Akron, Akron, OH 44325, USA. E-mail: jzhu1@ uakron.edu; Tel: +13309726859

${ }^{b}$ Division of Machine Elements, Luleå University of Technology, Luleå, 97187, Sweden ${ }^{c}$ Department of Chemical and Biomolecular Engineering, University of Tennessee, Knoxville, TN 37996, USA

${ }^{d}$ Department of Physics and Astronomy, Louisiana State University, Baton Rouge, LA 70803, USA

$\dagger$ Electronic supplementary information (ESI) available. See DOI: 10.1039/c5ra19616g most promising process due to its low cost, simple operation as well as its capability can produce water of high quality.

Porous carbon, especially activated carbon, is well accepted as effective adsorbent in water purification. However, the relatively high manufacturing cost restricts its wide applications simply because the corrosive chemicals such as $\mathrm{ZnCl}_{2}$ or $\mathrm{KOH}$ have to be used during the activation process. These chemicals not only add up the cost but also pose potential secondary environmental pollutions. Over the past decade, biomass derived carbon has aroused great interest in the research field and also find wide application in energy storage such as sodium ion battery, ${ }^{18}$ supercapacitor ${ }^{19,20}$ as well as environmental remediation in adsorption based water purification. ${ }^{\mathbf{1 6 2 1 - 2 3}}$ Researchers have fabricated carbon adsorbents from various biomass resources, such as cotton, ${ }^{21}$ bamboo, ${ }^{24}$ vetiver roots, ${ }^{25}$ oil palm wood, ${ }^{26}$ rattan sawdust, ${ }^{27}$ rice husk, ${ }^{28,29}$ banana stalk, ${ }^{30}$ peanut shell ${ }^{31}$ and successfully used them as adsorbents for either heavy metal or organic pollutants removal from polluted water. Adsorbents those are capable of removing both organic and inorganic pollutants are of great interest and practically useful, while very rare work has been reported so far with both capabilities.

In general, carbon materials show superior adsorption capacity after activation, which is attributed to the significantly 
enlarged surface area and increased surface hydrophilicity that facilitates the diffusion and adhesion of pollutant molecules inside the adsorbent. However, the overall adsorption performance of biomass derived carbon is still not satisfying compared to commercial activated carbon, which demands further structural and functional design to realize practical applicability. In general, macropores and mesopores are considered access points to micropores. It is the micropores in carbon that plays a significant role in adsorption. ${ }^{32}$ Previous study reveals that mesopores, with pore size in the range of 2-50 $\mathrm{nm}$, could significantly improve the diffusivity of small molecules inside the pore channels. ${ }^{33}$ To realize efficient diffusion and adsorption of small molecules in biomass derived carbon, the existence of macro-/meso-pore channels and microporous adsorption sites are equally important. Even though mesopore size can be well controlled from bottom-up synthesis via hardtemplate $^{34-36}$ and soft-template methods, ${ }^{37-39}$ it still remains a great challenge to create mesopores in biomass derived carbon from a top-down approach. Conventional physical and chemical activation generally creates micropores those are not ideal structure for internal mass transfer. Our previous work demonstrated that penetrating mesoporous structure can be created via a simple thermal oxidation process in spruce-pinefir derived carbon, which out-performs commercial activated carbon in organic dye adsorption. ${ }^{40}$ However, this simple method relies on the thermal degradation of lignin to create mesopores, which does not necessarily works for other biomass derived carbons. One typical example is natural cotton that consists of almost $100 \%$ cellulose without lignin. Therefore, an alternative approach needs to be developed to create mesopores in lignin-free biomass.

In this work, mesopores have been successfully created in cotton derived carbon through an in situ catalytic graphitization approach. The microstructure of the synthesized materials was carefully investigated by different characterization techniques. Adsorption isotherms and kinetic studies were conducted to quantify the adsorption capacity and rate, respectively. These materials show outstanding adsorption performance in organic dyes (positively charged methylene blue and negatively charged methyl orange) and more interestingly selective heavy metal adsorption. The pollutants removal mechanisms were also studied in this work.

\section{Experimental}

\subsection{Preparation of carbon and carbon nanocomposites}

Cotton fabric was cut from commercially available T-shirt made of $100 \%$ cotton. Iron nitrate (>98\%) was purchased from Sigma Aldrich. Methylene blue (MB) and methyl orange (MO) were purchased from Fisher Scientific. Nickel(II) chloride hexahydrate $(>98 \%)$, zinc chloride $(>97 \%)$, copper(II) chloride dihydrate (98\%) and lead chloride (99\%) were purchased from Acros Organics. Potassium dichromate $(99.8 \%)$ was purchased from Fisher Scientific. All chemicals were used as-received without further treatment. Carbon nanocomposites were prepared from a facile two-step procedure, impregnation and carbonization. First, $4.0 \mathrm{~g}$ of cotton fabrics were soaked in $40 \mathrm{~mL} 0.1,0.3,0.5$ and 1.0 $\mathrm{M}$ iron nitrate solutions in a vacuum oven for 24 hours. Then the soaked cotton fabrics were carefully blotted and dried at room temperature overnight. Then the dried cotton fabrics were carbonized at $800{ }^{\circ} \mathrm{C}$ for 2 hours in nitrogen atmosphere with a heating rate of $5{ }^{\circ} \mathrm{C} \mathrm{min}^{-1}$. As a control, original cotton fabric was carbonized directly without the soaking process and the sample was named C-00M. Carbonized samples pre-soaked with $0.1,0.3,0.5$ and $1.0 \mathrm{M}$ iron nitrate solutions were denoted as C-01M, C-03M, C-05M and C-10M, respectively. To investigate the pore structure after removing metal nanoparticles, $1.0 \mathrm{~g}$ of nanocomposite (C-01M, C-03M, C-05M and C-10M) was mixed with $10.0 \mathrm{~mL} 1.0 \mathrm{M} \mathrm{HCl}$ aqueous solution for 12 hours. Then, the samples were filtered, washed with deionized water until the rinsing water was neutral and dried at $80{ }^{\circ} \mathrm{C}$ for 12 hours. Samples after acid washing were named C-01M(w), C-03M(w), C$05 \mathrm{M}(\mathrm{w})$ and $\mathrm{C}-10 \mathrm{M}(\mathrm{w})$, respectively.

\subsection{Material characterization}

The microstructure of C-00M, C-01M, C-03M, C-05M and C-10M was characterized by scanning electron microscopy (SEM, JEOL7401). Transmission electron microscopy (TEM) images of the prepared materials were obtained by JEOL JEM-1230 microscope. High-resolution TEM (HRTEM) images were taken using a FEI Tecnai G2 F20 microscope operated at $200 \mathrm{kV}$. The nanoparticle loading in the composites was determined by thermogravimetric analysis (TGA, TA instrument Q500) in air atmosphere from 20 to $800{ }^{\circ} \mathrm{C}$ with a ramp rate of $10{ }^{\circ} \mathrm{C} \mathrm{min}{ }^{-1}$. The powder X-ray diffraction analysis was carried out with a Bruker AXS D8 Discover diffractometer with GADDS (General Area Detector Diffraction System) operating with a $\mathrm{Cu}-\mathrm{K} \alpha$ radiation source filtered with a graphite monochromator. The specific surface area and pore-size distribution were measured on a TriStar II 3020 by nitrogen adsorption at $77.3 \mathrm{~K}$. The pore size distribution was calculated from the adsorption branch of the isotherm. Raman spectrum was obtained using a Horiba LabRam HR Micro Raman Spectrometer, equipped with a CCD camera detector within the range of $400-3000 \mathrm{~cm}^{-1}$. Zeta potential of C-00M and nanocomposites were determined by Malvern Zetasizer Nano-ZS90. To quantify the amount of iron ions leached into the polluted water during adsorption, inductively coupled plasma (ICP) analysis was performed on ICP-OES (Perkin Elmer P-400). The magnetic property was measured in a $9 \mathrm{~T}$ physical properties measurement system (PPMS) by Quantum Design.

\subsection{Organic dye and heavy metal adsorption}

To determine the adsorption capacity of the synthesized materials, $1.0 \mathrm{~g} \mathrm{~L}^{-1}$ of C-00M, C-01M, C-03M, C-05M and C-10M were used to treat $10 \mathrm{~mL} \mathrm{MB}$ and $\mathrm{MO}$ solutions with different initial concentrations at room temperature. The treatment time was set at 12 hours to ensure equilibrium has reached. After treatment, the mixture was filtered and the solution was characterized by UV-Vis spectrometer to determine the remaining dye concentration. For kinetic studies, $1.0 \mathrm{~g} \mathrm{~L}^{-1}$ of C-01M, C-03M, C$05 \mathrm{M}$ and $\mathrm{C}-10 \mathrm{M}$ were used to treat $40 \mathrm{~mL} 50 \mathrm{ppm} \mathrm{MB}$ or MO solution with sampling time of 1, 3, 5, 7, 10, 15 and $30 \mathrm{~min}$. Due 
to the low adsorption capacity of $\mathrm{C}-00 \mathrm{M}$, the initial $\mathrm{MB}$ concentration was chosen as $10 \mathrm{ppm}$ with sampling time of 1,3 , 10, 60, 120 and $180 \mathrm{~min}$. Temperate effect on the dye removal kinetics was performed with $1.0 \mathrm{~g} \mathrm{~L}^{-1} \mathrm{C}-10 \mathrm{M}$ in $50 \mathrm{ppm} \mathrm{MB/MO}$ solutions at different temperatures of 25,45 and $65{ }^{\circ} \mathrm{C}$. Standard curves relating the dye concentration and UV-Vis adsorption peak intensity at $664 \mathrm{~nm}$ (MB) and $465 \mathrm{~nm}$ (MO) are constructed to determine the remaining dye concentration after removal tests.

Adsorption of heavy metal ions were comparatively investigated with C-00M and C-03M. Specifically, $0.05 \mathrm{~g}$ C-00M or C$03 \mathrm{M}$ was added to $50 \mathrm{~mL}$ aqueous mixture with $25 \mathrm{ppm}$ of each following ions: $\mathrm{Cu}^{2+}, \mathrm{Zn}^{2+}, \mathrm{Cr}^{6+}, \mathrm{Pb}^{2+}$ and $\mathrm{Ni}^{2+}$ under magnetic stirring. $3.0 \mathrm{~mL}$ of the mixture was collected, filtered and acidified for ICP analysis at time interval of 1, 2, 4, 6 and 10 hours.

For cycling tests, 50 ppm MB and 25 ppm metal ion mixtures were used separately. Adsorbent after $\mathrm{MB}$ adsorption was regenerated in a tube furnace at $500{ }^{\circ} \mathrm{C}$ for 1 hour under nitrogen atmosphere. Adsorbent after metal ion adsorption was regenerated by acid washing with $0.1 \mathrm{M} \mathrm{HCl}$. The adsorption capacity from first cycle was recorded as 100\%. Adsorption capacity in following cycles versus the first cycle value was calculated as retention.

\section{Results and discussion}

\subsection{Microstructure investigation}

Fig. 1(a) showed the microstructure of pure cotton fiber after annealing. The fibrous structure of cotton was well maintained after the annealing process with helical structure and the fiber diameter is about $10 \mu \mathrm{m}$. Focusing on the surface, wrinkled texture appeared along the axial direction of fiber, which is consistent with the natural assembly pattern of cellulose fibrils. Compared to the relatively smooth surface of C-00M (Fig. 1(b)), uniformly distributed nanoparticles were observed in the nanocomposites, Fig. 1(c-f). The nanoparticle size largely depends on the concentration of the iron precursor. Specifically, the particle size is only $22.9 \pm 5.2$ and $49.0 \pm 8.1 \mathrm{~nm}$ for C$01 \mathrm{M}$ and $\mathrm{C}-03 \mathrm{M}$. With further increasing initial precursor concentration, the particle size increased to $104.8 \pm 18.2$ and $178.3 \pm 36.6 \mathrm{~nm}$ for C-05M and C-10M, respectively. The larger particle size at higher precursor concentration is mainly due to the nanoparticle aggregation during annealing. Besides, it is worth mentioning that deeper wrinkled surface texture was developed after introducing nanoparticles. It's well known that volume shrinkage usually occurred during carbonization, which is a homogeneous shrinking process. After introducing nanoparticles, catalytic graphitization accelerates the shrinking process and meanwhile induces heterogeneous shrinkage. Thus, much rougher surface textures were observed in the nanocomposites as compared to C-00M.

To further examine the effect of nanoparticles on the morphology and crystalline structure of nanocomposites, comparative TEM and HRTEM studies were performed on C$00 \mathrm{M}$ and C-03M. C-00M showed amorphous feature, where no lattice fringe could be observed in Fig. 2(a). In C-03M,
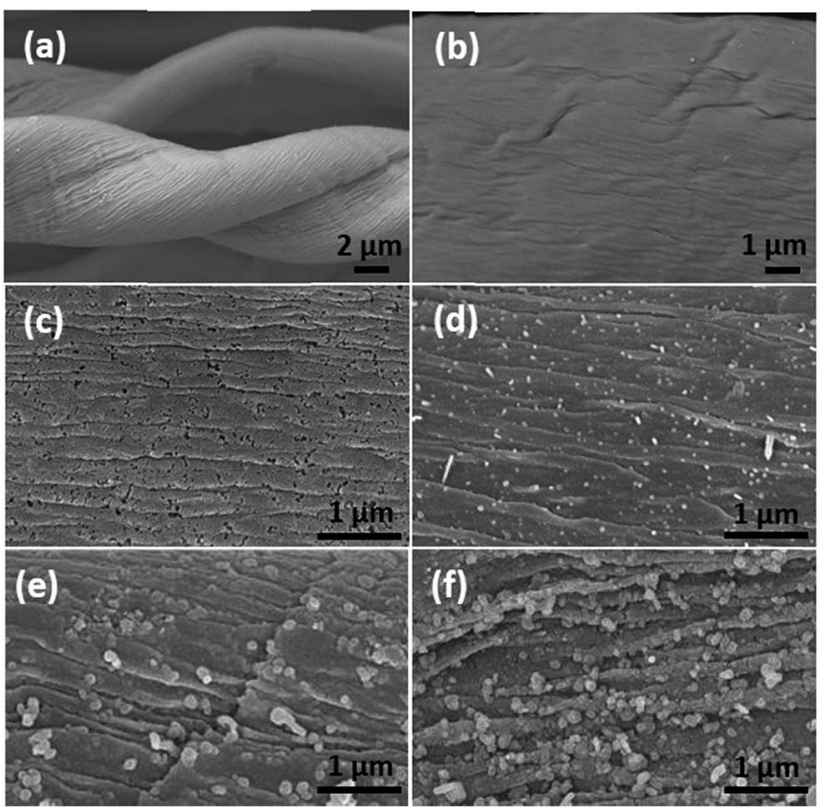

Fig. 1 SEM microstructures of (a \& b) C-00M, (c) C-01M, (d) C-03M, (e) C-05M and (f) C-10M.

nanoparticles were uniformly distributed in the carbon matrix, Fig. 2(b). HRTEM images focusing on one nanoparticle show typical core-shell structure, Fig. 2(c). The lattice fringe of the shell was measured as $0.35 \mathrm{~nm}$, which is indexed to the lattice spacing of graphite. The lattice fringe of the encapsulated core area was determined as $0.21 \mathrm{~nm}$ that can be assigned to the (031) crystalline plane of $\mathrm{Fe}_{3} \mathrm{C}$, Fig. 2(d). ${ }^{18,41}$ The catalytic graphitization of other biomass like soft wood was conducted by Thompson et al. ${ }^{22}$ and our group ${ }^{23}$ recently and both observed graphitized carbon and mesopore formation in the carbonized products. A few key steps for the catalytic graphitization has been proposed: (1) thermal decomposition of iron precursor $\mathrm{Fe}\left(\mathrm{NO}_{3}\right)_{3}$ to form iron oxide nanoparticles; (2) carbothermal reduction of iron oxide to produce $\mathrm{Fe}_{3} \mathrm{C}$ nanoparticles. Firstly, iron oxide is reduced by carbon reductant to form elemental iron nanoparticles, and subsequently elemental iron further reacts with carbon to form $\mathrm{Fe}_{3} \mathrm{C}$ nanoparticles; (3) migration of $\mathrm{Fe}_{3} \mathrm{C}$ nanoparticles to catalyze the reaction from amorphous carbon to graphitized carbon through the carbon matrix. It is worth mentioning that $\mathrm{Fe}_{3} \mathrm{C}$ is in liquid state at 800 ${ }^{\circ} \mathrm{C}$ and can migrate freely on carbon matrix. Along the migration path, amorphous carbon will be catalyzed into graphite carbon and leaves behind a hollow tube structure as seen in Fig. 2(e). Accompanies with the catalytic reaction, carbon volume shrink would be expected due to the more orderly-packed crystalline structure and mesopores will be generated between graphitized carbons that will be discussed in later section of this work.

To further confirm the crystalline structure of nanoparticles, $\mathrm{X}$-ray diffraction patterns of annealed samples were recorded, Fig. 2(f). Only one broad peak at $2 \theta \approx 20^{\circ}$ was observed in C$00 \mathrm{M}$, indicating its amorphous nature. This is in good agreement with TEM results. For all the other nanocomposites, the appearance of a sharp graphite peak at around $2 \theta=25.9^{\circ}(\mathrm{PDF}$ 

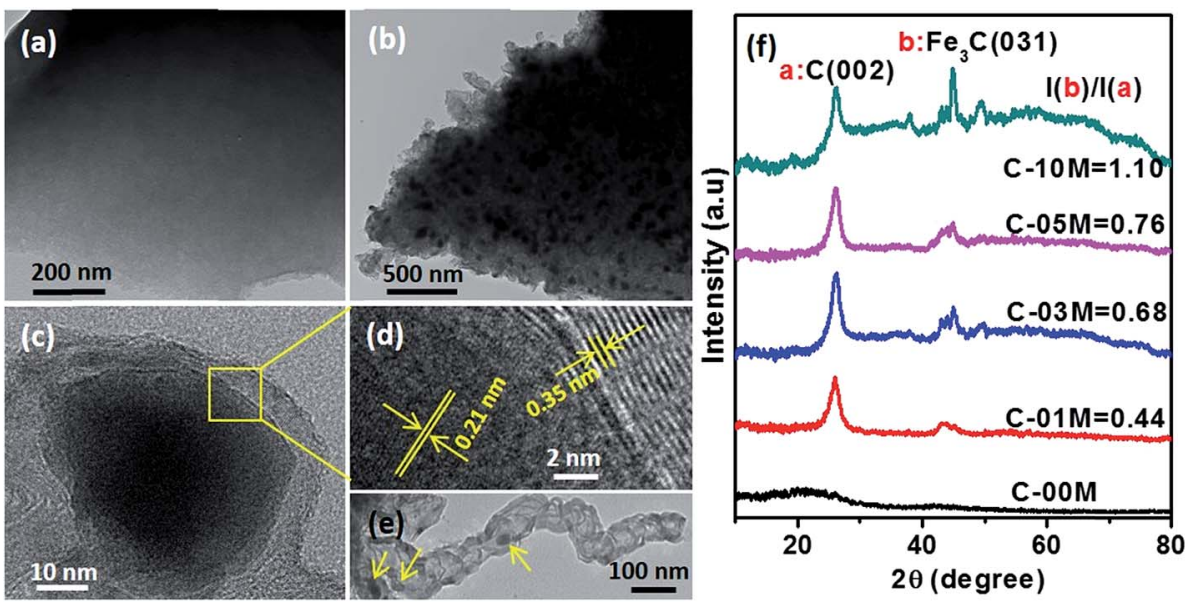

Fig. 2 TEM images of (a) C-00M, (b) C-03M, (c \& d) HRTEM images of C-03M, (e) $\mathrm{Fe}_{3} \mathrm{C}$ nanoparticles in the center of a graphitized carbon tube with arrows indicated and (f) XRD patterns of C-00M, C-01M, C-03M, C-05M and C-10M. /(b)//(a) indicates the ratio of peak intensity Fe $3(031) /$ C(002).

\# 41-1487) confirmed the formation of graphitic carbon C(002). Also, the peaks appeared at $2 \theta=43.7,45.0$ and $49.1^{\circ}$ are indexed to the (102), (031) and (221) crystal planes of $\mathrm{Fe}_{3} \mathrm{C}$ (PDF \# 35-0772). Besides, the peak intensity ratio of $\mathrm{Fe}_{3} \mathrm{C}$ (031)/ graphite $\mathrm{C}(002)$ increased gradually from 0.44 to 1.10 with increasing nanoparticle loading, Fig. 2(f), indicating the increased portion of $\mathrm{Fe}_{3} \mathrm{C}$ in the nanocomposites relative to the graphitized carbon. The graphitization degree in nanocomposites can be calculated by Mering-Maire eqn (1):42

$$
g=\frac{0.3440-d_{002}}{0.3440-0.3354}
$$

where $g$ is graphitization degree, 0.3440 indicates the layer distance of non-graphitized carbon, 0.3354 is the layer distance of $100 \%$ graphitized carbon and $d_{002}$ is the layer distance of sample, which can be calculated from Bragg eqn (2):

$$
2 d \sin \theta=n \lambda
$$

where $d$ is the spacing between the planes in the atomic lattice, $\theta$ is the angle between the incident ray and the scattering planes, $n$ is an integer, and $\lambda$ is the wavelength of incident wave $(\lambda=1.54056 \AA)$. The graphitization degree for C-01M, C-03M, C$05 \mathrm{M}$ and $\mathrm{C}-10 \mathrm{M}$ was calculated as $12.1,38.6,50.8$ and $45.6 \%$, respectively. It seems that larger graphitization degree can be achieved by doping more nanoparticles (C-01M $\rightarrow$ C-05M) due to the provided more active sites for catalytic graphitization. However, further increasing nanoparticle loading (C-10M) leads to severe aggregation and reduced active sites and thus decreased graphitization degree was observed in $\mathrm{C}-10 \mathrm{M}$ than that of C-05M.

TGA analysis was performed to determine the actual $\mathrm{Fe}_{3} \mathrm{C}$ loading in the nanocomposites, as shown in Fig. 3. C-00M began to degrade at $\sim 400{ }^{\circ} \mathrm{C}$ and the $1.6 \%$ final residue is attributed to the non-degradable inorganics, Fig. S1. $\dagger$ In the nanocomposites, a slight weight increase was observed starting from $250{ }^{\circ} \mathrm{C}$, which is caused by the oxidation of $\mathrm{Fe}_{3} \mathrm{C}$ in air. With further increasing temperature to $\sim 400{ }^{\circ} \mathrm{C}$, the $\mathrm{Fe}_{3} \mathrm{C}$ in nanocomposites was fully oxidized to $\mathrm{Fe}_{2} \mathrm{O}_{3}$ and the carbon was completely burned out afterwards, Fig. 3(a). The final residue at $800{ }^{\circ} \mathrm{C}$ is composed of $\mathrm{Fe}_{2} \mathrm{O}_{3}$ and non-degradable inorganics. To calculate $\mathrm{Fe}_{3} \mathrm{C}$ loading in the nanocomposites, weight fraction of non-degradable inorganics was subtracted and weight percentage of $\mathrm{Fe}_{2} \mathrm{O}_{3}$ was converted to $\mathrm{Fe}$ and $\mathrm{Fe}_{3} \mathrm{C}$ in corresponding nanocomposite as summarized in Table 1.

The specific surface area and average pore size of C-01M, C$03 \mathrm{M}, \mathrm{C}-05 \mathrm{M}$ and $\mathrm{C}-10 \mathrm{M}$ were determined by nitrogen adsorption-desorption isotherm at $77.3 \mathrm{~K}$, Fig. 3(c). C-00M shows typical microporous structure with a specific surface area of $396.5 \mathrm{~m}^{2} \mathrm{~g}^{-1}$, Fig. S2. $\dagger$ Fig. $3(\mathrm{c})$ reveals that all nanocomposites show typical type-IV curves, which confirmed the existence of mesopores. At relatively low pressure, samples first experience monolayer adsorption, followed by multilayer adsorption, while at higher pressure region, the adsorbed volume increased continuously due to capillary condensation inside mesopores. ${ }^{43,44}$ All the hysteresis loops closed sharply at $P / P_{0} \approx 0.44$ due to the existence of "ink-bottle" pores, which usually has a narrow entrance but large internal space. The BET surface area, apparent surface area (excluding the mass of $\mathrm{Fe}_{3} \mathrm{C}$ ), average pore diameter, pore volume and apparent pore volume (excluding the mass of $\mathrm{Fe}_{3} \mathrm{C}$ ) obtained from adsorption branches were summarized in Table 1. Among the nanocomposites, the highest surface area of $410.0 \mathrm{~m}^{2} \mathrm{~g}^{-1}$ was achieved with lowest nanoparticle loading in C-01M. The specific surface area decreases gradually with increasing nanoparticle loading, e.g. surface area of $251.7,176.2$ and $154.0 \mathrm{~m}^{2} \mathrm{~g}^{-1}$ was obtained in C-03M, C- $05 \mathrm{M}$ and $\mathrm{C}-10 \mathrm{M}$, respectively. The decreased specific surface area is majorly attributed to the expanded pore size as well as the mass contribution of heavier $\mathrm{Fe}_{3} \mathrm{C}$ nanoparticles. By excluding the weight fraction of $\mathrm{Fe}_{3} \mathrm{C}$ from the nanocomposites, apparent surface area was calculated and summarized in Table 1. As discussed before, the catalytic graphitization facilitates the mesopore formation. Therefore, samples with higher $\mathrm{Fe}_{3} \mathrm{C}$ loading possesses more mesopores instead of micropores and thus smaller specific surface area, 

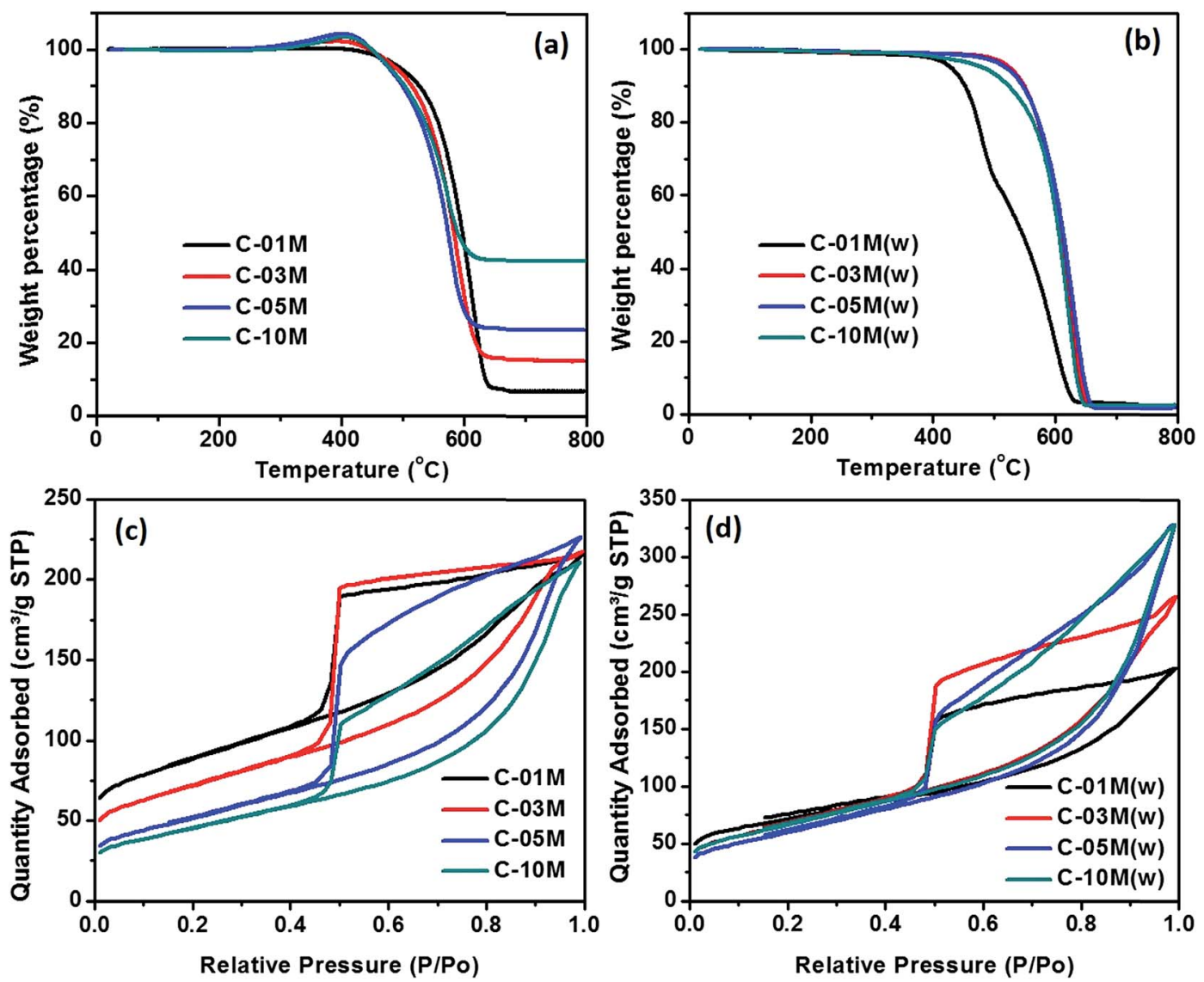

Fig. 3 TGA curves of $C-x x M(x x=00,01,03,05$ and 10) nanocomposites (a) before and (b) after acid washing with $1 \mathrm{M} \mathrm{HCl} \mathrm{acid.} \mathrm{BET} \mathrm{isotherms} \mathrm{of}$ $\mathrm{C}-x x \mathrm{M}$ nanocomposites (c) before and (d) after acid washing. The TGA and BET results of C-00M are provided in ESI Fig. S1 and S2. $\dagger$

which is in good agreement with the apparent surface area in Table 1 except for $\mathrm{C}-10 \mathrm{M}$ where nanoparticle aggregation became dominant. Similarly, by excluding the mass of $\mathrm{Fe}_{3} \mathrm{C}$, apparent pore volume was calculated, Table 1 . The apparent pore volume increased sharply from $0.03(\mathrm{C}-00 \mathrm{M})$ to $0.17 \mathrm{~cm}^{3}$ $\mathrm{g}^{-1}(\mathrm{C}-01 \mathrm{M})$ and then stabilized at $0.29-0.30 \mathrm{~cm}^{3} \mathrm{~g}^{-1}$ for nanocomposites with higher loadings. The pore size distribution in the micropore region is calculated by density functional theory (DFT) method from $\mathrm{CO}_{2}$ adsorption branch, and the one in the mesopore region is calculated by Barret Joyner and Halenda (BJH) method from $\mathrm{N}_{2}$ adsorption branch. The combined pore size distribution is shown in Fig. S3. $\dagger$ The average pore diameter increased gradually from 3.9 to $5.9 \mathrm{~nm}$ with increasing nanoparticle loading majorly because of the expanded pore structure induced by the heterogeneous shrinkage during catalytic graphitization.

To understand the contribution of nanoparticle to the microstructure formation of the nanocomposites, an acid

Table 1 Summary of material properties before and after acid washing ${ }^{a}$

\begin{tabular}{|c|c|c|c|c|c|c|c|c|c|c|}
\hline Sample & $\begin{array}{l}\text { Residues@800 } \\
{ }^{\circ} \mathrm{C}, \mathrm{wt} \%\end{array}$ & $\begin{array}{l}\mathrm{Fe}_{2} \mathrm{O}_{3} \\
\text { wt } \%\end{array}$ & $\begin{array}{l}\mathrm{Fe}_{3} \mathrm{C} \\
\mathrm{wt} \%\end{array}$ & $\begin{array}{l}S_{\text {total }} \\
\mathrm{m}^{2} \mathrm{~g}^{-1}\end{array}$ & $\begin{array}{l}S_{\text {Int }}, \\
\mathrm{m}^{2} \mathrm{~g}^{-1}\end{array}$ & $\begin{array}{l}S_{\text {Ext. }}, \\
\mathrm{m}^{2} \mathrm{~g}^{-1}\end{array}$ & $\begin{array}{l}S_{\text {apparent }}{ }^{*}, \\
\mathrm{~m}^{2} \mathrm{~g}^{-1}\end{array}$ & $\begin{array}{l}V_{\text {pore }} \\
\mathrm{cm}^{3} \mathrm{~g}^{-1}\end{array}$ & $\begin{array}{l}V_{\text {apparent }}{ }^{*}, \\
\mathrm{~cm}^{3} \mathrm{~g}^{-1}\end{array}$ & $\begin{array}{l}D_{\text {pore }} \\
\mathrm{nm}\end{array}$ \\
\hline C-00M & 1.6 & 0 & 0 & 396.5 & 351.0 & 45.5 & 396.5 & 0.03 & 0.03 & —** \\
\hline C-03M & 15.1 & 13.5 & 10.1 & 251.7 & 46.9 & 204.8 & 278.0 & 0.25 & 0.29 & 5.4 \\
\hline C-05M & 23.7 & 22.1 & 16.6 & 176.2 & 1.0 & 175.2 & 211.3 & 0.24 & 0.29 & 5.9 \\
\hline C-10M & 42.6 & 41 & 30.8 & 154.0 & 0.3 & 153.8 & 222.5 & 0.21 & 0.30 & 5.8 \\
\hline $\mathrm{C}-05 \mathrm{M}(\mathrm{w})$ & 1.7 & 0.1 & 0.1 & 204.4 & 0 & 204.4 & 204.6 & 0.31 & 0.31 & 5.8 \\
\hline $\mathrm{C}-10 \mathrm{M}(\mathrm{w})$ & 2.4 & 0.8 & 0.6 & 228.0 & 0 & 228.0 & 229.4 & 0.40 & 0.40 & 5.8 \\
\hline
\end{tabular}

$a *$ Surface area calculated on per gram of pure carbon. **Average pore size not available due to the large portion of micropores. C- $x \times \mathrm{M}(\mathrm{w})$ indicates the C- $x x \mathrm{M}$ after $1.0 \mathrm{M} \mathrm{HCl}$ acid washing. 


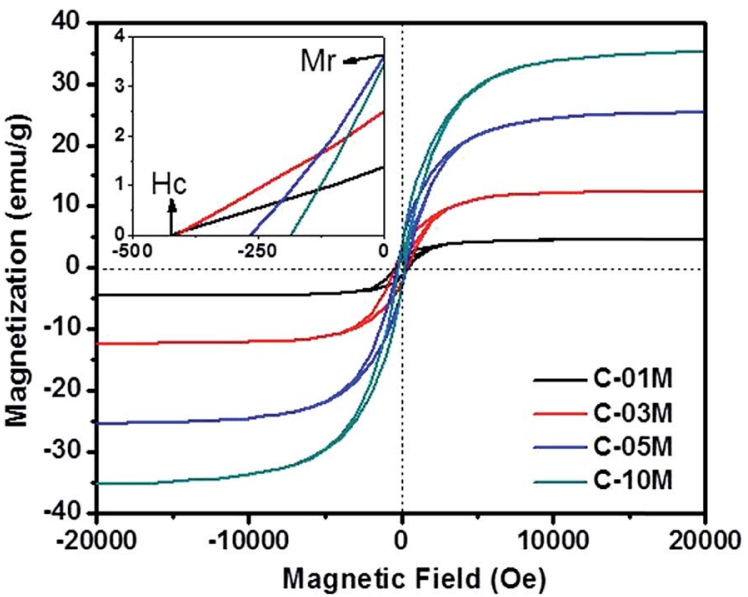

Fig. 4 Magnetic property of C-01M, C-03M, C-05M and C-10M.

etching step by $1.0 \mathrm{M} \mathrm{HCl}$ was applied to remove the metallic component of the nanocomposites. The solid residue after thermal decomposition is about the same for all the etched samples as compared to C-00M, Fig. 3(b), indicating the iron species can be completely removed. The total surface area distributes within the range of 204.4-254.9 $\mathrm{m}^{2} \mathrm{~g}^{-1}$ with negligible internal surface area in $\mathrm{C}-03 \mathrm{M}(\mathrm{w}), \mathrm{C}-05 \mathrm{M}(\mathrm{w})$ and $\mathrm{C}-$ $10 \mathrm{M}(\mathrm{w})$, Fig. $3(\mathrm{~d})$ and Table 1. Comparing the apparent pore volume results of the nanocomposites before and after acid washing, it is obvious that new pores were generated after removing the iron element. Especially, 33\% higher apparent volume is observed in $\mathrm{C}-10 \mathrm{M}(\mathrm{w})$ than that of $\mathrm{C}-10 \mathrm{M}$, indicating a large portion of nanoparticles were embedded inside the bulk carbon rather than at the surface. These embedded nanoparticles are responsible for the newly generated pores.

The magnetic property of the nanocomposites is plotted in Fig. 4. Considering the weight fraction of $\mathrm{Fe}_{3} \mathrm{C}$ in each C- $x x \mathrm{M}$ $(x x=01,03,05$ and 10) nanocomposites and the saturated magnetization of $140 \mathrm{emu} \mathrm{g}^{-1}$ of bulk $\mathrm{Fe}_{3} \mathrm{C},{ }^{41}$ the calculated magnetization value is in good agreement with the measured results of 4.6, 12.4, 25.4 and $35.3 \mathrm{emu} \mathrm{g}^{-1}$ in C-01M, C-03M, C$05 \mathrm{M}$ and $\mathrm{C}-10 \mathrm{M}$, respectively. The coercivity $\left(H_{\mathrm{c}}, \mathrm{Oe}\right)$ indicates (a)<smiles>CN(C)c1ccc2nc3ccc(=[N+](C)C)cc-3sc2c1</smiles>

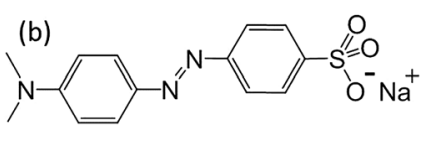

Scheme 1 Molecular structure of (a) MB and (b) MO.

the external applied magnetic field necessary to return the material to a zero magnetization condition, and the remnant magnetization $\left(M_{\mathrm{r}}\right)$ is the residue magnetization after the applied field is reduced to zero. Both values can be read from the axes crossing points, inset of Fig. 4. The coercivity decreases continuously from 425 to 184 Oe with increasing nanoparticle loading. The decreased coercivity indicates the $\mathrm{Fe}_{3} \mathrm{C}$ nanoparticles become magnetically softer due to the increased interparticle dipolar interaction arising from the decreased nanoparticle spacer distance for the single domain nanoparticles. ${ }^{45,46}$

\subsection{Organic dye adsorption}

To determine the dye concentration in polluted water, highly linear standard curves relating dye concentration and UV-Vis peak intensity have been plotted for MB at wavelength of 664 $\mathrm{nm}$ and $\mathrm{MO}$ at $450 \mathrm{~nm}$, Fig. S4 and S5. $\dagger$ Remaining dye concentration in treated water can be obtained by referencing to the corresponding peak intensity from standard curves. To quantify the adsorption capacity of C-00M, C-01M, C-03M, C- $05 \mathrm{M}$ and C-10M, isotherm adsorption was performed at room temperature for 12 hours. The isotherm adsorption results were then analyzed by Langmuir model, eqn (3):

$$
\frac{c_{\mathrm{e}}}{q_{\mathrm{e}}}=\frac{c_{\mathrm{e}}}{q_{\max }}+\frac{1}{q_{\max } k_{1}}
$$

where $c_{\mathrm{e}}$ and $q_{\mathrm{e}}$ are dye concentration remained in the solution $\left(\mathrm{mg} \mathrm{L}^{-1}\right.$ ) and the amount of dye adsorbed onto adsorbent $(\mathrm{mg}$ $\left.\mathrm{g}^{-1}\right)$ at equilibrium, respectively. $q_{\max }$ is the maximum adsorption capacity $\left(\mathrm{mg} \mathrm{g}^{-1}\right)$ and $k_{1}$ represents the energy constant related to the energy of adsorption. $q_{\mathrm{e}}$ can be calculated by eqn (4):
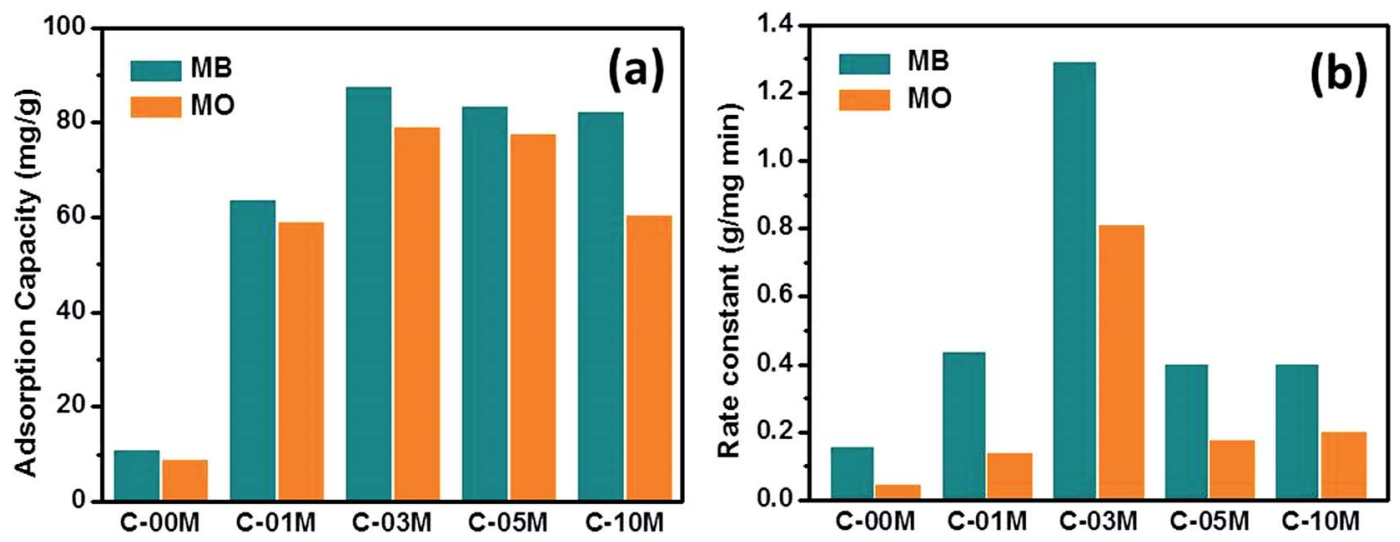

Fig. 5 (a) Adsorption capacity and (b) adsorption rate constant of $C-x x M(x x=00,01,03,05$ and 10$)$ with $M B$ and $M O$. 

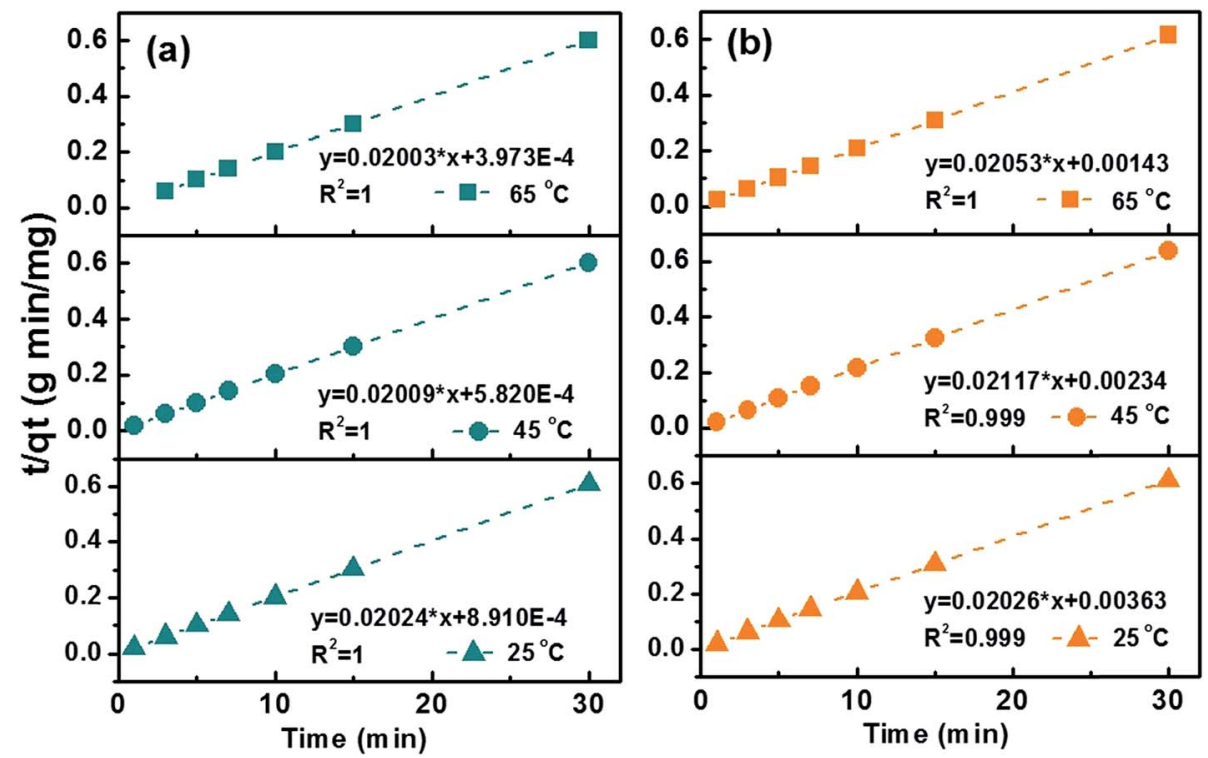

Fig. 6 Transformed rate plot $t / q_{t}$ vs. $t$ with linear fitting for (a) $\mathrm{MB}$ and (b) $\mathrm{MO}$ at 25,45 and $65^{\circ} \mathrm{C}$ with $\mathrm{C}-10 \mathrm{M}$.

$$
q_{\mathrm{e}}=\frac{c_{0}-c_{\mathrm{e}}}{m / V}
$$

where $c_{0}$ and $c_{\mathrm{e}}$ are initial and equilibrium pollutant concentrations $\left(\mathrm{mg} \mathrm{L}^{-1}\right), m$ is the mass of adsorbent $(\mathrm{g})$ and $V$ is volume of polluted solution (L). $q_{\max }$ and $k_{1}$ can be determined from the slope and interception of the linearly fitted $c_{\mathrm{e}} / q_{\mathrm{e}} \sim c_{\mathrm{e}}$ curve.

The $q_{\text {max }}$ obtained from Langmuir model and rate constant calculated from pseudo-second order model were shown in Fig. 5( $\mathrm{a}$ and $\mathrm{b})$. The details of the non-linear fitting are provided in Fig. S6-S9. $\dagger$ For pure carbon C-00M, the $q_{\text {max }}$ is measured as 10.7 and $8.7 \mathrm{mg} \mathrm{g}^{-1}$ for $\mathrm{MB}$ and MO, respectively. The nanocomposites show more than 5 times larger adsorption capacity compared to C-00M. The improved adsorption capacity is mainly attributed to the newly created mesoporous structure, which provides sufficient large pore channels for dye molecule diffusion and extra active sites for adsorption. Although the maximum adsorption capacity is relatively low compared to activated carbon, the adsorption efficiency (defined as: mg dye per $\mathrm{m}^{2}$ adsorbent) is relatively larger compared to activated carbon manufactured from other biomass resources, Table S1. $\dagger$ All the tested samples show higher adsorption capacity for MB rather than $\mathrm{MO}$, even though $\mathrm{MB}$ molecule has relatively larger hydrodynamic radius of $\sim 4.9 \AA$ (ref. 47 ) compared to $\sim 4.5 \AA$ (ref. 48) of MO. Organic dye adsorption on carbon materials has been explained by strong $\pi-\pi$ stacking in previous literature. ${ }^{\mathbf{4 9}}$ Considering the molecular structures of MB and MO as seen in Scheme 1, it is obvious that MB shows higher order of conjugation, where the free electrons are more centralized within the domain of benzene and six-membered hetero-ring. Thus, stronger $\pi-\pi$ interaction could be expected between MB and adsorbents that leads to higher adsorption capacity.

Similar to the results from isotherm study, rate constant of the nanocomposites is much higher than pure carbon and highest adsorption rate was achieved in C-03M, Fig. 5(b). Different from isotherm results, all samples show obviously higher adsorption rate for $\mathrm{MB}$, which could be attributed to the different interaction modes between adsorbate and adsorbent. Zeta potential was then measured on each sample and it was found that all the samples exhibit negative surface potential, Fig. S10, $\uparrow$ indicating the surfaces are negatively charged. When negative surface encounters cationic MB molecules, charge attraction dominates the interfacial interaction and consequently leads to faster adsorption rate. However, when negative surface encounters anionic MO molecules, charge repulsion force dominates the interfacial behavior and thus results in smaller rate constant.

Kinetic studies were then conducted at three different temperatures, 25,45 and $65{ }^{\circ} \mathrm{C}$ to quantify adsorption rate and activation energy, Fig. 6. Pseudo-second-order model demonstrated the highest fitting accuracy $\left(R^{2}>0.999\right)$ among the four tested models including pseudo-first-order, pseudo-secondorder, intraparticle diffusion, and Elovich models, which can be described with eqn (5):

$$
\frac{t}{q_{t}}=\frac{1}{q_{\mathrm{e}}^{2} k_{2}}+\frac{t}{q_{\mathrm{e}}}
$$

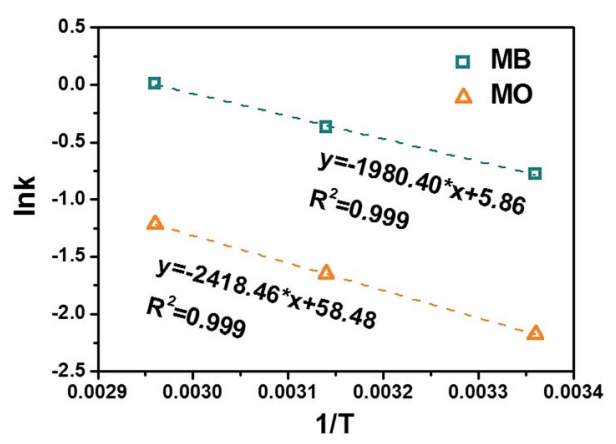

Fig. 7 Arrhenius plot of MB and MO with C-10M. 

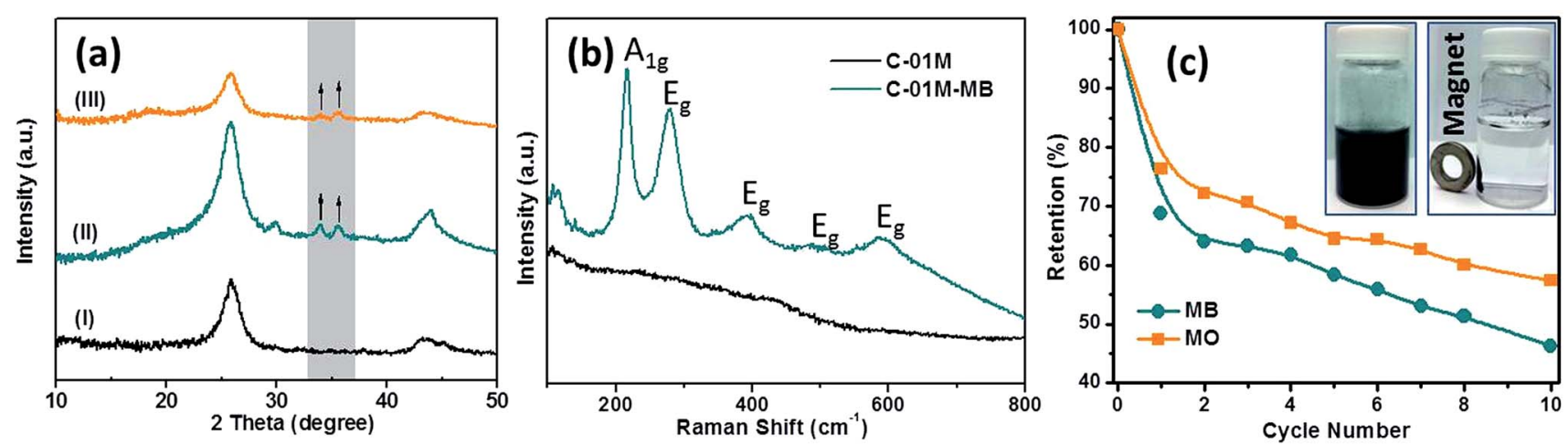

Fig. 8 XRD patterns of C-01M (a-I) before and after absorbing (a-II) MB and (a-III) MO, (b) Raman spectrum of C-01M before and after absorbing $\mathrm{MB}$, and (c) cycling retention tests of C-01M, the two insets showed C-01M in water before (left) and after (right) attraction by a permanent magnet.

where $t$ is the sampling time ( $\mathrm{min}$ ), $q_{t}$ is the dye concentration at time $t, q_{\mathrm{e}}$ is the amount of dye adsorbed on to adsorbent $(\mathrm{mg}$ $\mathrm{g}^{-1}$ ) at equilibrium. $k_{2}$ is the pseudo-second-order rate constant $\left(\mathrm{g} \mathrm{mg}^{-1} \mathrm{~min}^{-1}\right)$. The values of $q_{\mathrm{e}}$ and $k_{2}$ can be determined from the slope and intercept of the plot of $t / q_{t}$ against $t$. Generally, the rate constant increases with increasing adsorption temperature for both MB (0.46, 0.69 and $1.01 \mathrm{~g} \mathrm{mg}^{-1} \mathrm{~min}^{-1}$ at 25, 45 and 65 $\left.{ }^{\circ} \mathrm{C}\right)$ and $\mathrm{MO}\left(0.11,0.19\right.$ and $0.29 \mathrm{~g} \mathrm{mg}^{-1} \mathrm{~min}^{-1}$ at 25,45 and 65 ${ }^{\circ} \mathrm{C}$ ). Compared to previous literatures, ${ }^{50-52}$ the expedited adsorption rate could be attributed to the hybrid meso-/microporous structure which facilitate the fast diffusion of pollutant molecules to active sites. The increased rate constant at higher temperature is attributed to the accelerated diffusion of dye molecules.

With known rate constant at different temperatures, activation energy $E_{\mathrm{a}}$ can be determined based on the Arrhenius equation, eqn (6):

$$
\ln \left(k_{2}\right)=\frac{-E_{\mathrm{a}}}{R} \frac{1}{T}+\ln (A)
$$

where $T$ is the absolute temperature (K), $A$ is the pre-exponential factor, $E_{\mathrm{a}}$ is the activation energy, and $R$ is the universal gas constant. By linear fitting the $\ln (k) \sim 1 / T$ plot, Fig. 7, the $E_{\mathrm{a}}$ can be determined as $16.5 \mathrm{~kJ} \mathrm{~mol}^{-1}$ for $\mathrm{MB}$ and $20.1 \mathrm{~kJ} \mathrm{~mol}^{-1}$ for MO. The higher $E_{\mathrm{a}}$ in removing MO is likely caused by the electrostatic repulsion between the adsorbent and MO molecules.

To understand the removal mechanism, XRD patterns of C01M were collected before and after dye adsorption, Fig. 8. The newly formed peaks at $2 \theta=30.5,33.8$ and $35.7^{\circ}$ after absorbing $\mathrm{MB}$ are indexed to (220), (310) and (311) crystal planes of $\mathrm{Fe}_{2} \mathrm{O}_{3}$ (PDF \# 02-1047), Fig. 8(a-II), indicating the redox reaction also occurred between $\mathrm{Fe}_{3} \mathrm{C}$ nanoparticles and $\mathrm{MB}$ molecules during adsorption. Similar peaks were also found in C-01M after absorbing MO, Fig. 8(a-III). Raman spectrum further confirms the oxidized form of iron with the newly formed Raman modes of $A_{1 \mathrm{~g}}$ and $E_{\mathrm{g}},{ }^{53}$ Fig. 8(b). To test recyclability of adsorbent, C-01M was firstly exposed to excess amount of MB (or MO) solutions for 12 hours and then regenerated in $\mathrm{N}_{2}$ atmosphere at $500^{\circ} \mathrm{C}$ for 1 hour with a heating rate of $10{ }^{\circ} \mathrm{C} \mathrm{min}^{-1}$. The adsorption capacity retention up to 10 cycles was shown in Fig. 8(c). The major adsorption capacity loss is occurred during 1 st cycle, which accounts for $31.3 \%$ for MB and $23.7 \%$ for MO. Afterwards, slower capacity loss was
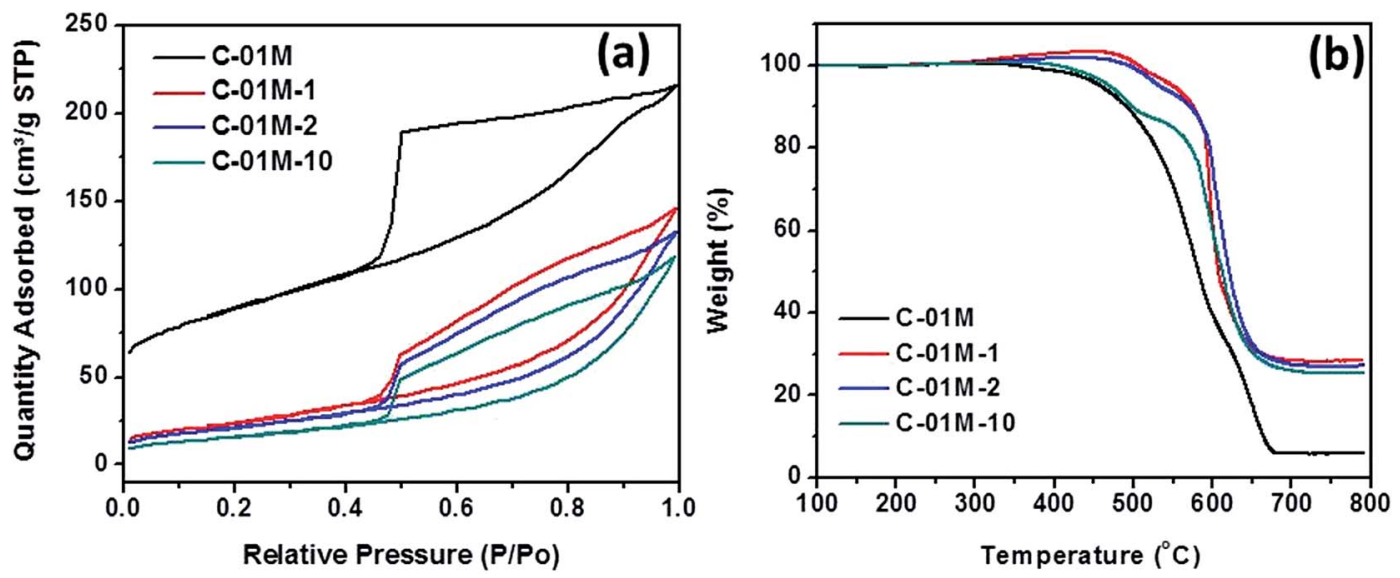

Fig. 9 (a) BET isotherms and (b) TGA of C-01M after different regeneration cycles. 
observed in the following 9 cycles with 10th cycle retention of $57 \%$ and $46 \%$ for MO and MB respectively. To monitor the possible iron leaching during adsorption, the iron concentration was continuously measured with ICP in the testing solution for up to 10 hours. Results reveal that the iron level is $<0.1 \mathrm{ppm}$ with organic dye adsorption and $<0.4 \mathrm{ppm}$ with metal ion adsorption, Fig. S11. $\dagger$ Therefore, the secondary pollution by possible iron leaching could be neglected.

The adsorbent $\mathrm{C}-01 \mathrm{M}$ is further characterized by BET and TGA to analyze the structure and component change after regeneration. The as-prepared $\mathrm{C}-01 \mathrm{M}$ and $\mathrm{C}-01 \mathrm{M}$ after $1 \mathrm{st}, 2 \mathrm{nd}$ and 10th regeneration (named C-01M, C-01M-1, C-01M-2 and C$01 \mathrm{M}-10$ ) were selected for analysis. It is obvious that the major pore structural change occurred after 1st regeneration with significant decrease of surface area from 410 to $79 \mathrm{~m}^{2} \mathrm{~g}^{-1}$ and increase of average pore size from 3.9 to $6.1 \mathrm{~nm}$, Fig. 9(a). After 1st regeneration, the weight percentage of carbon in C-01M dropped from 94.6 to $80.0 \mathrm{wt} \%$, Fig. 9(b). The structural and composition of C-01M do not change significantly from 2 nd to 10th regeneration (Fig. 9), which well explains the relatively slow decay of adsorption capacity after 1st regeneration.

\subsection{Selective heavy metal removal}

Fig. 10 shows the metal ion residue percentage in solution as a function of adsorption time. The adsorption equilibrium can be reached within 2 hours by using C-00M adsorbent and it shows selective adsorption for different metal ions $\mathrm{Cr}$ (VI) $>\mathrm{Zn}$ (II) $>\mathrm{Ni}$ (II) $>\mathrm{Cu}$ (II) $>\mathrm{Pb}$ (II), Fig. 10(a). After 10 hours adsorption, over $60 \%$ of all the metal ions are still remained in the water, especially for $\mathrm{Pb}(\mathrm{II})$ with over $90 \%$ remained. For $\mathrm{C}-03 \mathrm{M}$, the adsorption continuously proceeds within the first 10 hours probably due to the gradual diffusion of pollutants from external surface (mesopores) to inner surface (micropores). More interestingly, it shows higher selectivity towards more toxic species such as $\mathrm{Cr}(\mathrm{VI})$ and $\mathrm{Pb}$ (II) rather than less toxic $\mathrm{Cu}(\mathrm{II})$, $\mathrm{Zn}$ (II) and $\mathrm{Ni}$ (II) ions. Also, it's worth mentioning that no $\mathrm{Cr}(\mathrm{VI})$ can be detected in the remaining solution after 24 hours adsorption. Two possible mechanisms are proposed to explain

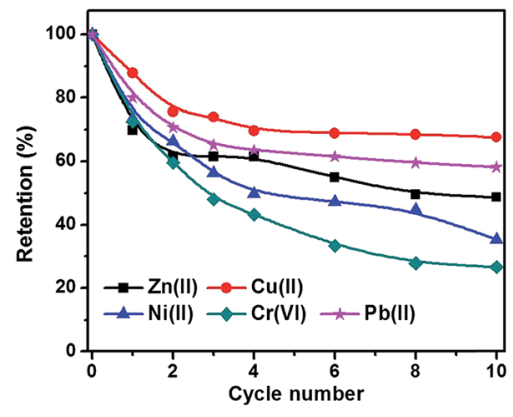

Fig. 11 Cycling retention tests for heavy metal ion adsorption.

the higher adsorption capacity of C-03M compared to C-00M. Firstly, the larger pore size of $\mathrm{C}-03 \mathrm{M}$ provides easy-accessible adsorption sites for heavy metal ion adsorption. Secondly, the more negative zeta potential of C-03M $(-25.64 \mathrm{mV})$ than C-00M $(-11.28 \mathrm{mV})$, Fig. $\mathrm{S} 10, \dagger$ leads to stronger electrostatic interaction between adsorbent and cationic heavy metals ions and thus larger adsorption capacity. The adsorption capacity of metal ions with C-03M follows the order of $\mathrm{Cr}$ (VI) $>\mathrm{Pb}$ (II) $>\mathrm{Cu}$ (II) $>\mathrm{Ni}$ (II) $>\mathrm{Zn}$ (II). Isotherm was then performed with different initial metal ion concentrations of 25, 50, 75 and $100 \mathrm{ppm}$ and the fitting results with Freundlich isotherm model were summarized in, Table $\mathrm{S} 2 . \dagger$ The adsorption capacity parameter $K_{\mathrm{f}}$ in Table S $2 \uparrow$ shows high consistency with the adsorption results in Fig. 10(b). Generally, selective adsorption of heavy metals can be achieved by grafting functional groups ${ }^{54-57}$ and imprint specific ion species, ${ }^{\mathbf{5 8}}$ which require extra step for surface functionalization not even mention the chemicals involved during material preparation. Since the mesopore size in the nanocomposites (in $\mathrm{nm}$ order) is much larger than the hydrodynamic radius of the metal ions (in $\AA$ order), it is not supposedly to restrict ion movement through gating-effect. Therefore, the selectivity is attributed to the interfacial interaction, e.g. electrostatic attraction and ion exchange, ${ }^{59}$ between embedded iron carbide nanoparticles and adsorbates. The adsorption capacity for each metal ion decreases with increasing regeneration cycles with
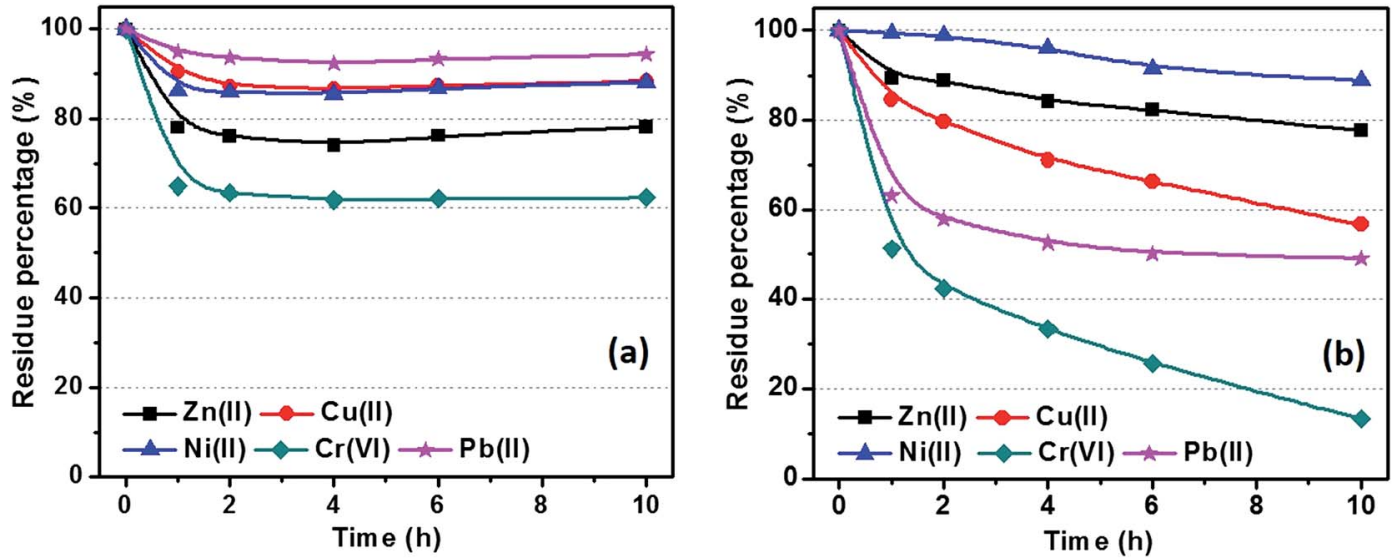

Fig. 10 Isothermal adsorption of metal ions with (a) C-00M and (b) C-03M. [Adsorbent] $=1.0 \mathrm{~g} \mathrm{~L}^{-1}$, [metal ion] $=25.0 \mathrm{ppm}$ and volume of tested solution: $40.0 \mathrm{~mL}$. 
observed major decrease during the first three cycles, Fig. 11. The adsorption of $\mathrm{Cr}(\mathrm{vI})$ degrades the fastest among the five metal ions ( $\sim 30 \%$ remaining after 10 cycles), followed by $\mathrm{Ni}(\mathrm{II})$, $\mathrm{Zn}$ (II), $\mathrm{Pb}$ (II) and $\mathrm{Cu}(\mathrm{II})$. One major advantage of the nanocomposites prepared in this work is the achieved superior selectivity towards more toxic metal ion species without additional surface modification procedure.

\section{Conclusion}

In sum, mesoporous carbon/iron carbide nanocomposites have been synthesized via a facile impregnation-carbonization process by using sustainable biomass-cotton as source material. The pore structure of the nanocomposites can be easily regulated by adjusting iron catalyst loading during carbonization (catalytic graphitization) and large surface area of $>300 \mathrm{~m}^{2} \mathrm{~g}^{-1}$ can be obtained. The graphitization induced mesopores are demonstrated essential structural component for the significantly enhanced adsorption capacity for organic dyes. The embedded iron carbide are responsible for the highly selectivity towards toxic heavy metal ions. Kinetic study reveals the pseudo-second-order adsorption behavior with organic dyes. Adsorption capacitance retention can be stabilized after regeneration. Besides, the magnetic property of these nanocomposites facilitates their easy separation from pollutant solution by a permanent magnet. The unique dual function towards both organic dye and heavy metal adsorption allows this mesoporous carbon/iron carbide nanocomposites promising applications in practical polluted water treatment not only because the effective adsorption property but also the widely accessible raw material, easy fabrication, low cost and minimum environmental impacts.

\section{Acknowledgements}

Acknowledgement is made to the Donors of the American Chemical Society Petroleum Research Fund for support of this research (\#55570-DNI10). Partial support from start-up fund, Faculty Research Committee, Biomimicry Research Incentive Center and Firestone Faculty Research Fellowship from The University of Akron are also acknowledged. DPY acknowledges support from the NSF under grant no. DMR1306392. HRTEM was performed at the Liquid Crystal Institute, Kent State University supported by the Ohio Research Scholars Program Research Cluster on Surfaces in Advanced Materials. The authors appreciate the technical support from Dr Min Gao with HRTEM.

\section{References}

1 A. J. Whelton, L. McMillan, M. Connell, K. M. Kelley, J. P. Gill, K. D. White, R. Gupta, R. Dey and C. Novy, Environ. Sci. Technol., 2015, 49, 813-823.

2 N. S. Galbraith, N. J. Barrett and R. Stanwell-Smith, Water Environ. J., 1987, 1, 7-21.

3 L. West, http://www.environment.about.com/od/environmental events/a/waterdayqa.htm, 2006.
4 J. Li, C. Chen, S. Zhang and X. Wang, Environ. Sci.: Nano, 2014, 1, 488-495.

5 S. Zhu, S. Jiao, Z. Liu, G. Pang and S. Feng, Environ. Sci.: Nano, 2014, 1, 172-180.

6 J. Zhu, S. Wei, H. Gu, S. B. Rapole, Q. Wang, Z. Luo, N. Haldolaarachchige, D. P. Young and Z. Guo, Environ. Sci. Technol., 2011, 46, 977-985.

7 J. Zhu, H. Gu, S. B. Rapole, Z. Luo, S. Pallavkar, N. Haldolaarachchige, T. J. Benson, T. C. Ho, J. Hopper, D. P. Young, S. Wei and Z. Guo, RSC Adv., 2012, 2, 4844-4856.

8 M. Li, C. Wang, M. J. O'Connell and C. K. Chan, Environ. Sci.: Nano, 2015, 2, 245-250.

9 S. S. Lee, W. Li, C. Kim, M. Cho, J. G. Catalano, B. J. Lafferty, P. Decuzzi and J. D. Fortner, Environ. Sci.: Nano, 2015, 2, 500508.

10 A. G. El Samrani, B. S. Lartiges and F. Villiéras, Water Res., 2008, 42, 951-960.

11 W.-P. Zhu, S.-P. Sun, J. Gao, F.-J. Fu and T.-S. Chung, J. Membr. Sci., 2014, 456, 117-127.

12 Z. Thong, G. Han, Y. Cui, J. Gao, T.-S. Chung, S. Y. Chan and S. Wei, Environ. Sci. Technol., 2014, 48, 13880-13887.

13 W.-P. Zhu, J. Gao, S.-P. Sun, S. Zhang and T.-S. Chung, J. Membr. Sci., 2015, 487, 117-126.

14 H. Li and L. Zou, Desalination, 2011, 275, 62-66.

15 X. Meng, D. A. Vaccari, J. Zhang, A. Fiume and X. Meng, Environ. Sci. Technol., 2014, 48, 1541-1548.

16 C. E. Barrera-Díaz, V. Lugo-Lugo and B. Bilyeu, J. Hazard. Mater., 2012, 223-224, 1-12.

17 N. Kongsricharoern and C. Polprasert, Water Sci. Technol., 1995, 31, 109-117.

18 X. Wang, P. Zhang, W. Wang, X. Lei and H. Yang, RSC Adv., 2015, 5, 57828-57832.

19 J. Zhu, M. Chen, H. Wei, N. Yerra, N. Haldolaarachchige, Z. Luo, D. P. Young, T. C. Ho, S. Wei and Z. Guo, Nano Energy, 2014, 6, 180-192.

20 J. Zhu, M. Chen, N. Yerra, N. Haldolaarachchige, S. Pallavkar, Z. Luo, T. C. Ho, J. Hopper, D. P. Young, S. Wei and Z. Guo, Nanoscale, 2013, 5, 1825-1830.

21 J. Zhu, H. Gu, J. Guo, M. Chen, H. Wei, Z. Luo, H. A. Colorado, N. Yerra, D. Ding, T. C. Ho, N. Haldolaarachchige, J. Hopper, D. P. Young, Z. Guo and S. Wei, J. Mater. Chem. A, 2014, 2, 2256-2265.

22 E. Thompson, A. E. Danks, L. Bourgeois and Z. Schnepp, Green Chem., 2015, 17, 551-556.

23 L. Chen, H. Wang, H. Wei, Z. Guo, M. A. Khan, D. P. Young and J. Zhu, RSC Adv., 2015, 5, 42540-42547.

24 B. H. Hameed, A. T. M. Din and A. L. Ahmad, J. Hazard. Mater., 2007, 141, 819-825.

25 S. Altenor, B. Carene, E. Emmanuel, J. Lambert, J.-J. Ehrhardt and S. Gaspard, J. Hazard. Mater., 2009, 165, 1029-1039.

26 A. L. Ahmad, M. M. Loh and J. A. Aziz, Dyes Pigm., 2007, 75, 263-272.

27 B. H. Hameed, A. L. Ahmad and K. N. A. Latiff, Dyes Pigm., 2007, 75, 143-149.

28 N. R. Bishnoi, M. Bajaj, N. Sharma and A. Gupta, Bioresour. Technol., 2004, 91, 305-307. 
29 M. Ahmaruzzaman and V. K. Gupta, Ind. Eng. Chem. Res., 2011, 50, 13589-13613.

30 J. M. Salman and B. H. Hameed, J. Hazard. Mater., 2010, 176, 814-819.

31 Z. A. Al-Othman, R. Ali and M. Naushad, Chem. Eng. J., 2012, 184, 238-247.

32 P. Serp and B. Machado, in Nanostructured Carbon Materials for Catalysis, The Royal Society of Chemistry, 2015, ch. 1, pp. $1-45$.

33 L. Chuenchom, R. Kraehnert and B. M. Smarsly, Soft Matter, 2012, 8, 10801-10812.

34 S. A. Johnson, E. S. Brigham, P. J. Ollivier and T. E. Mallouk, Chem. Mater., 1997, 9, 2448-2458.

35 J. Rodriguez-Mirasol, T. Cordero, L. R. Radovic and J. J. Rodriguez, Chem. Mater., 1998, 10, 550-558.

36 Y. Zhai, Y. Dou, D. Zhao, P. F. Fulvio, R. T. Mayes and S. Dai, Adv. Mater., 2011, 23, 4828-4850.

37 J. S. Lee, A. Hirao and S. Nakahama, Macromolecules, 1988, 21, 274-276.

38 M. Templin, A. Franck, A. Du Chesne, H. Leist, Y. Zhang, R. Ulrich, V. Schädler and U. Wiesner, Science, 1997, 278, 1795-1798.

39 Y. Wan, X. Cui and Z. Wen, J. Hazard. Mater., 2011, 198, 216223.

40 L. Chen, T. Ji, L. Brisbin and J. Zhu, ACS Appl. Mater. Interfaces, 2015, 7, 12230-12237.

41 A. Wu, D. Liu, L. Tong, L. Yu and H. Yang, CrystEngComm, 2011, 13, 876-882.

42 J. Maire and J. Mering, in Chemistry and Physics of Carbon, ed. P. L. Walker and J. A. Thrower, Dekker, New York, 1971, vol. 6, pp. 125-190.

43 K. Morishige and N. Tarui, J. Phys. Chem. C, 2007, 111, 280285.
44 D. Wallacher, N. Künzner, D. Kovalev, N. Knorr and K. Knorr, Phys. Rev. Lett., 2004, 92, 195704.

45 Z. Guo, K. Lei, Y. Li, H. W. Ng, S. Prikhodko and H. T. Hahn, Compos. Sci. Technol., 2008, 68, 1513-1520.

46 J. Zhu, S. Wei, X. Chen, A. B. Karki, D. Rutman, D. P. Young and Z. Guo, J. Phys. Chem. C, 2010, 114, 8844-8850.

47 M. Majumder, P. Sheath, J. I. Mardel, T. G. Harvey, A. W. Thornton, A. Gonzago, D. F. Kennedy, I. Madsen, J. W. Taylor, D. R. Turner and M. R. Hill, Chem. Mater., 2012, 24, 4647-4652.

48 J. F. Urban, Nonlinear, Spatiotemporal Hydrogel Dynamics in Oscillatory Drug Release, University of Minnesota, doctoral dissertation, 2008.

49 F. Liu, S. Chung, G. Oh and T. S. Seo, ACS Appl. Mater. Interfaces, 2011, 4, 922-927.

50 H. Deng, J. Lu, G. Li, G. Zhang and X. Wang, Chem. Eng. J., 2011, 172, 326-334.

51 L. Liu, Y. Lin, Y. Liu, H. Zhu and Q. He, J. Chem. Eng. Data, 2013, 58, 2248-2253.

52 S. Karagöz, T. Tay, S. Ucar and M. Erdem, Bioresour. Technol., 2008, 99, 6214-6222.

53 S.-H. Shim and T. S. Duffy, Am. Mineral., 2002, 87, 318-326. 54 A. M. Liu, K. Hidajat, S. Kawi and D. Y. Zhao, Chem. Commun., 2000, 1145-1146.

55 J. Brown, L. Mercier and T. J. Pinnavaia, Chem. Commun., 1999, 69-70.

56 C. Liu, R. Bai and Q. San Ly, Water Res., 2008, 42, 1511-1522.

57 T. Kang, Y. Park and J. Yi, Ind. Eng. Chem. Res., 2004, 43, 1478-1484.

58 G.-Z. Fang, J. Tan and X.-P. Yan, Anal. Chem., 2005, 77, 17341739.

59 J. Hu, G. Chen and I. Lo, J. Environ. Eng., 2006, 132, 709-715. 